\title{
Blackberry Cultivar Feeding Preference of Adult Japanese Beetles
}

\author{
Maciej A. Pszczolkowski' ${ }^{1}$ Kyndra Chastain, Rachel Veenstra, \\ and Martin L. Kaps \\ Darr College of Agriculture, Missouri State University, 9740 Red Spring \\ Road, Mountain Grove, MO 65711
}

Additional index words. Popillia japonica, feeding damage, plant resistance to insect pests

\begin{abstract}
The Japanese beetle (Popillia japonica Newman) is one of the most widespread and destructive invasive insect pests in the eastern United States. Blackberry (Rubus sp.) production in the United States has increased significantly in recent years. With the introduction of new blackberry cultivars, insect resistance should become the focus of further breeding efforts. The objective of the current study was to evaluate the susceptibility of 13 blackberry cultivars to the Japanese beetle. The seasonal population dynamics of this insect, beetle damage to blackberry foliage, and beetle preference of blackberry cultivars were monitored from 2016 to 2018 on a blackberry plantation in Mountain Grove, MO. Japanese beetles feeding on blackberries occurred between 814 to 1251 cumulative degree-days $\left(\mathrm{CDD} ;\right.$ base, $10^{\circ} \mathrm{C}$ ) after $1 \mathrm{Jan}$. The following cultivars were evaluated: Apache, APF-40, Arapaho, Chester, Chickasaw, Kiowa, Natchez, Osage, Ouachita, Prime-Ark 45, Prime-Jan, Prime-Jim, and Triple Crown. Foliage damage incidence, defined as average percentage of leaves damaged by beetles on a given cane, did not differ among the cultivars. However, average severity of damage, estimated by rating on a scale from 0 (least) to 5 (most) of all damaged leaves on a given cane was different among cultivars. Ouachita and APF-40 exhibited the lowest damage severity rating among floricanes and primocanes, respectively. Apache (a floricane) and Prim-Jan (a primocane) were the most susceptible cultivars. Japanese beetle preferences for cultivars correlated with the degree of foliage damage. Because all blackberry cultivars exhibited similar foliage feeding incidence, but different feeding severity, we suggest the Japanese beetle does not differentiate among blackberry cultivars from a distance, but does upon contact with the foliage of a given plant.
\end{abstract}

The Japanese beetle (Popillia japonica Newman) is an invasive beetle belonging to the family of Scarabaeidae. First discovered in Riverton, NJ, in 1916 (Fleming, 1976), it is one of the most widespread and destructive insect pests in the eastern United States. The direct cost of renovating or replacing turf damaged by larval root pruning and defoliation of ornamental plants by adults has been estimated to exceed $\$ 450$ million each year (Potter and Held, 2002). Adult Japanese beetles attack mostly the foliage, flowers, and fruit of more than 300 plant species in 79 families (Fleming, 1972).

Japanese beetles have one generation per year in the areas in which blackberries are cultivated commercially. The larvae of this species overwinter in the soil, then pupate in the ground and emerge as adults in early summer (Tashiro, 1987). After emergence, adult beetles disperse and aggregate on plants

Received for publication 7 Dec. 2018. Accepted for publication 1 Mar. 2019.

This research was supported by statutory funds provided by Missouri State University.

We thank Shelia Long, Jeremy Emery, Randy Stout, and Jessica Veenstra for their help in the field. Dr. Chin-Feng Huang and Marilyn Odneal reviewed the manuscript prior to submission. ${ }^{1}$ Corresponding author. E-mail: MPszczolkowski@ missouristate.edu. in close proximity to the areas where they have overwintered, and they then mate. Gravid females lay eggs in the ground, starting a new generation. Both sexes damage the plants by skeletonizing leaves and feeding on flowers.

In the United States, production of cultivated blackberries exceeds $30,000 \mathrm{t}$ yearly (Clark and Finn, 2011; Strik et al., 2007), making the United States the second largest producer of blackberries in the world. Blackberry production area increased by more than $30 \%$ between 1995 and 2005, and Strik et al. (2007) predicted a further increase of $30 \%$ by 2015 . Clark and Finn (2011) have listed several reasons for this increase, emphasizing the introduction of new blackberry cultivars with improved shipping characteristics. They have also pointed out that disease and insect resistance should become the focus for further breeding efforts.

The Japanese beetle is a serious insect pest of blackberries (Clark and Finn, 2011). Control of this pest is possible using pesticides. However, identification of blackberry cultivars with natural resistance to Japanese beetles could help to minimize environmental pollution and worker exposure to chemicals. This area of research is heavily understudied. We were able to locate only one article that investigated this issue (Johnson et al., 2010). The authors of that report evaluated the damage from Japanese beetles on 18 blackberry cultivars in Fayetteville,
AR, by visually rating the degree of canopy defoliation. They found that Apache was the most sensitive, and PrimeJan was the most resilient cultivar.

The objectives of our study are to compare seasonal changes in population densities of Japanese beetles, CDD to peak beetle emergence, differences in percentages of blackberry leaves in canopies infested with Japanese beetles (damage incidence), and ratings of severity of leaf damage among 13 blackberry cultivars.

\section{Materials and Methods}

Blackberry plantation and weather data collection. The research took place from 2016 to 2018. The blackberries were planted on the experimental farm at the Missouri State University Research Campus in Mountain Grove, MO (lat. $37^{\circ} 9^{\prime} \mathrm{N}$, long. $92^{\circ} 16^{\prime} \mathrm{W}$; elevation, $442 \mathrm{~m}$ ). The 0.07 -ha plantation consisted of 13 blackberry (Rubus sp.) cultivars planted in a randomized complete block design with four two-plant replications. Plant spacing was $1.5 \mathrm{~m}$ in row with $3.7 \mathrm{~m}$ between rows. The blackberry plants were managed as biennial canes and were trained between the wires of a double-T trellis. No tipping was done. The following cultivars were evaluated: Apache, APF-40, Arapaho, Chester, Chickasaw, Kiowa, Natchez, Osage, Ouachita, Prime-Ark 45, Prime-Jan, Prime-Jim, and Triple Crown.

The soil was a Viraton series, cherty silt loam soil with a $2 \%$ to $5 \%$ slope, a pH of 6.7 , and an organic matter content of $2.4 \%$. A fragipan occurs at a depth of 60 to $90 \mathrm{~cm}$, which limits the water-holding capacity of the soil; thus, plants were drip-irrigated during periods of low rainfall. Nitrogen $(\mathrm{N})$ was applied annually, as urea, at $110 \mathrm{~kg} \cdot \mathrm{ha}^{-1}$. Phosphorus $(\mathrm{P})$ and potassium $(\mathrm{K})$ were maintained at acceptable levels by fertilizer additions ( $67 \mathrm{~kg} \cdot \mathrm{ha}^{-1}$ available $\mathrm{P}$ and $280 \mathrm{~kg} \cdot \mathrm{ha}^{-1}$ exchangeable K). Calcium, magnesium, and sulfur are typically adequate in native soil. Plant rows were mulched with shredded bark. Tall fescue (Festuca arundinacea Shreb.) grass was the permanent sod in the row middles.

Each year, in late February or March, two dormant insecticide/miticide or fungicide/ insecticide sprays were applied to the plantation, including Brigade 2EC at $448 \mathrm{~g} \cdot \mathrm{ha}^{-1}$ and Sulforix at $7.57 \mathrm{~L} \cdot \mathrm{ha}^{-1}$ in 2016 and 2017 , and Sulforix at $11.4 \mathrm{~L} \cdot \mathrm{ha}^{-1}$, and Fanfare 2EC at $\mathrm{g} \cdot \mathrm{ha}^{-1}$ in 2018. In June 2016, one spray with Mustang Max at $280 \mathrm{~g} \cdot \mathrm{ha}^{-1}$ was applied additionally. No insecticide sprays were applied in 2017 and 2018 after the aforementioned dormant insecticide/miticide applications.

Monitoring of Japanese beetle population. Sterling Rescue Japanese beetle yellow vane traps (Sterling International Inc., Spokane, WA) baited with both a floral and sex attractant were used to monitor beetle flight activity in 2017 and 2018. Seven traps were set individually on property poles at a height of $1.5 \mathrm{~m}$, at a distance of $15 \mathrm{~m}$ from the southern edge of the plantation. Lures were replaced 
weekly and traps were replaced every other week. Twenty-four hours after setting up the trap line, beetles were retrieved from the traps, moved to the laboratory, and counted. In some cases, the traps caught so many beetles that counting became impractical. In such cases, the volume of beetles in each trap sample was converted to numbers of adult Japanese beetle (100 mL equaled 350 beetles). The numbers of beetles were recorded as averages \pm the SE of the mean for every day of collection $(\mathrm{N}=7)$. Trap counts were recorded at 2- to 7-d intervals.

CDD from 1 Jan. up to each day of insect mum and minimum temperatures recorded

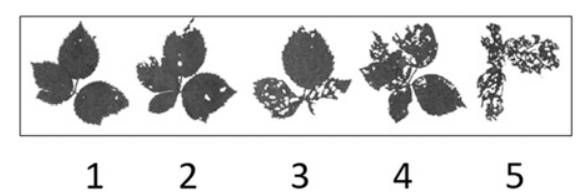

Fig. 1. The scoring system to estimate average level of blackberry leaf damage by the Japanese beetle on a damage scale from 1 (least) to 5 (most severe) for each cultivar. collection were calculated using daily maxi-

by computerized weather station located at a distance of $50 \mathrm{~m}$ from the north edge of the blackberry planting. These data were run using the single sine method on the online CDD calculator provided by University of California Agriculture and Natural Resources (Davis, CA). The base temperature was set at $10{ }^{\circ} \mathrm{C}$ on the basis of a report by Ludwig (1928).

Because the traps and lures we used in this study also attract oriental beetles, Anomala orientalis (Waterhouse), the contents of each trap were frozen and stored separately at $-24{ }^{\circ} \mathrm{C}$ for $48 \mathrm{~h}$. Later, these samples were inspected for the presence of the oriental beetle, but none were found.

Foliage damage. Blackberry foliage was inspected for Japanese beetle feeding damage in Aug. 2016 using the method of Johnson et al. (2010). This involved estimating visually the percentage of the canopy damaged by Japanese beetles. In Aug. 2017 and 2018, after the Japanese beetle adult population densities dropped to zero, two parameters of foliage damage by Japanese beetles were measured. One cane was selected at random from each plant of a given cultivar, cut off at ground level, labeled, and transported to the
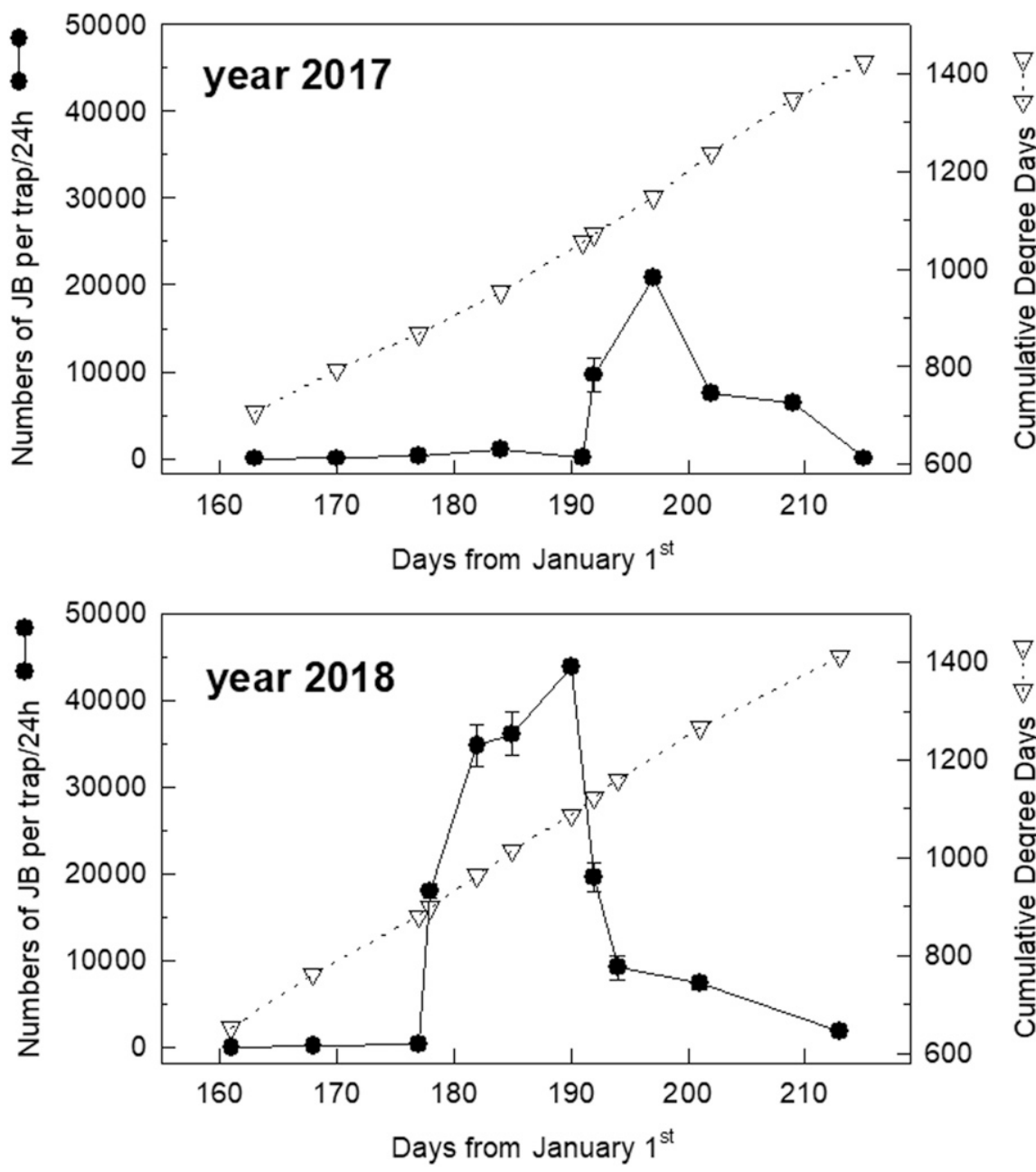

Fig. 2. Seasonal changes in cumulative degree-days (base, $10^{\circ} \mathrm{C}$ ) since $1 \mathrm{Jan}$. (triangles) vs. average baited trap captures of Japanese beetles (JBs; dots, averages $\pm \mathrm{SE}, \mathrm{N}=7$ ) on the blackberry plantation in Mountain Grove, MO, in 2017 and 2018. laboratory. The damage incidence was estimated by counting the numbers of leaves skeletonized by Japanese beetles on a single cane, and expressing these numbers as percentages of all the leaves present on the particular cane. We repeated this procedure four times for each cultivar. The damage severity, was estimated by rating each damaged leaf on a scale from 1 (the least damage) to 5 (the most severe damage) for each cultivar using three independent evaluators (Fig. 1). These scores were averaged and recorded. The increase in the degree of damage between the years of the experiment was calculated as a damage ratio by dividing the numerically expressed damage for 2018 by the respective numerical value for 2017 in each cultivar.

Cultivar preference by Japanese beetles. In June, July, and Aug. 2018, a field study was conducted to examine preferences of blackberry cultivars by Japanese beetles. Two primocane and two floricane cultivars were selected on the basis of the 2017 experiments (the most resistant and the most susceptible in each group): APF-40, Prime-Jan, Ouachita, and Apache. We selected individual canes randomly from each plant (10 canes for each cultivar). The number of Japanese beetles on each cane was recorded in the field, at 3- to 5-d intervals from $1000 \mathrm{HR}$ to $1200 \mathrm{HR}$, beginning from 13 June (first flight) until 10 Aug. (end of flight), and the corresponding CDD was calculated.

Data analysis. Data were analyzed by analysis of variance, followed by a Tukey comparison of means or by Student's $t$ test $(P<0.05)$, calculated using Graph Pad (San Diego, CA).

\section{Results}

Japanese beetle population dynamics. In both 2017 and 2018, the highest counts of Japanese beetles occurred between 1100 and 1200 CDD (Fig. 2). However, the highest counts per trap per $24 \mathrm{~h}$ differed significantly between the two years: $\approx 21,000$ beetles in 2017 vs. $\approx 44,000$ beetles in 2018 (Student's $t$ test, $\mathrm{t}=29.6, \mathrm{df}=12, P<0.05)$.

In addition, in 2018 , the beetle population was significantly more numerous during the $10 \mathrm{~d}$ preceding the peak (CDD, 899-1015), reaching $\approx 35,000$ beetles per trap per $24 \mathrm{~h}$ vs. $\approx 1000$ in the same time in 2017 (Student's $t$ test, $\mathrm{t}=13.8, \mathrm{df}=12, P<0.05)$.

Percentage of foliage damage. In both 2017 and 2018, there was no difference between the percentage of leaves damaged by the Japanese beetle among the four primocane (Table 1; Tukey, $\mathrm{F}=0.19$, $\mathrm{df}=15, P>0.05$ ) and nine floricane (Table 2; Tukey, $\mathrm{F}=0.53$, $\mathrm{df}=35, P>0.05)$ blackberry cultivars.

However, we found an increase in damage incidence between 2017 and 2018 within both primocane and floricane cultivars. In primocanes, damage increase ratios equaled 1.93 in 'APF-40' and 1.63 in 'Prime-Jan', and differences in foliage damage were statistically significant (Table 1; Student's $t$ test, $\mathrm{t}=3.25$, $\mathrm{df}=6, P<0.05$, and $\mathrm{t}=2.78, \mathrm{df}=6, P<0.05$, respectively). The same tendency was observed 
in floricane cultivars. Damage increase ratios equaled 1.76 in 'Apache', 1.90 in 'Osage', and 2.14 in 'Ouachita', and differences in foliage damage were also statistically significant (Table 2; Student's $t$ test, $\mathrm{t}=2.83$, df $=6$, $P<0.05 ; \mathrm{t}=5.12$, df $=6, P<0.05 ;$ and $\mathrm{t}=3.95, \mathrm{df}=6, P<0.05$, respectively).

Damage severity rating. In both 2017 and 2018 , differences were observed in the severity of foliage damage by Japanese beetles. Among the primocanes, in 2017, 'Prime-Jan' was the most susceptible to the Japanese beetle, whereas 'APF-40', 'Prime-Ark 45', and 'Prime-Jim' were significantly less susceptible (Table 3; Tukey, $\mathrm{F}=6.1, \mathrm{df}=309$, $P<0.05)$. We observed a similar tendency in 2018; 'Prime-Jan' was significantly more

susceptible to Japanese beetles than 'APF40' (Table 3; Student's $t$ test, $\mathrm{t}=5.2, \mathrm{df}=$ 214, $P<0.05)$

In 2017, Ouachita was the most resistant cultivar and Apache was the most susceptible cultivar among the floricanes. 'Natchez', 'Kiowa', 'Chickasaw', 'Osage', 'Triple Crown', 'Arapaho', and 'Chester' showed similar degrees of susceptibility to Japanese beetles, greater than that of 'Ouachita', but less than that of 'Apache' (Table 4; Tukey, $\mathrm{F}=20.9$, df $=806, P<$ 0.05). Similarly, in 2018, Ouachita was the most resistant cultivar and Apache was the most vulnerable cultivar. 'Osage' showed an intermediate degree of damage, similar to that of 'Ouachita', but less than that of

Table 1. Incidence of foliage damage by Japanese beetles on primocane blackberry cultivars in 2017 and 2018 in Mountain Grove, MO, recorded as the average percentage \pm sE. Measure of damaged leaves present on randomly selected canes of each cultivar $(\mathrm{N}=4)$.

\begin{tabular}{llcc}
\hline & \multicolumn{2}{c}{ Avg damage \pm SE $(\%)$} & \\
\cline { 2 - 3 } Cultivar & \multicolumn{1}{c}{2017} & 2018 & Damage increase ratio \\
\hline APF-40 & $42.3 \pm 10.3$ a A & $81.75 \pm 6.4$ a B & 1.93 \\
Prime-Ark 45 & $49.8 \pm 13.6$ a & n.t. & \\
Prime-Jim & $47.7 \pm 9.6 \mathrm{a}$ & n.t. & 1.63 \\
Prime-Jan & $53.5 \pm 7.5$ a A & $87.0 \pm 4.5$ a B & \\
\hline
\end{tabular}

Statistical significance of damage among the cultivars in a given year is indicated by lowercase letters. Values in columns followed by the same lowercase letters are not statistically significant (analysis of variance followed by Tukey comparison of means, $P>0.05$ ). Statistical significance of damage in the same cultivars between 2017 and 2018 is indicated by uppercase letters. Values in rows followed by the same uppercase letters are not statistically significant (Student's $t$ test, $P>0.05$ ).

n.t. $=$ not tested

Table 2. Incidence of foliage damage by Japanese beetles on floricane blackberry cultivars in 2017 and 2018 in Mountain Grove, MO, recorded as the average percentage \pm SE. Measure of damaged leaves present on randomly selected canes of each cultivar $(\mathrm{N}=4)$.

\begin{tabular}{llcc}
\hline & \multicolumn{2}{c}{ Avg damage \pm SE $(\%)$} & Damage increase ratio \\
\cline { 2 - 3 } Cultivar & \multicolumn{1}{c}{2017} & 2018 & 1.76 \\
\hline Apache & $46.3 \pm 15.1 \mathrm{a} \mathrm{A}$ & $99.0 \pm 0.7 \mathrm{a} \mathrm{B}$ & \\
Arapaho & $55.8 \pm 11.2 \mathrm{a}$ & n.t. & n.t. \\
Chester & $39.0 \pm 8.1 \mathrm{a}$ & n.t. & \\
Chickasaw & $39.5 \pm 11.5 \mathrm{a}$ & n.t. & 1.90 \\
Kiowa & $39.5 \pm 5.8 \mathrm{a}$ & n.t. & 2.14 \\
Natchez & $45.5 \pm 7.1 \mathrm{a} \mathrm{A}$ & $86.5 \pm 3.7 \mathrm{a} \mathrm{B}$ & \\
Osage & $42.0 \pm 7.7 \mathrm{a} \mathrm{A}$ & $90.0 \pm 3.9 \mathrm{a} \mathrm{B}$ & \\
Ouachita & $54.3 \pm 11.5 \mathrm{a}$ & n.t. & \\
Triple Crown &
\end{tabular}

Statistical significance of damage among the cultivars in a given year is indicated by lowercase letters. Values in columns followed by the same lowercase letters are not statistically significant (analysis of variance followed by Tukey comparison of means, $P>0.05)$. Statistical significance of damage in the same cultivars between 2017 and 2018 is indicated by uppercase letters. Values in rows followed by the same uppercase letters are not statistically significant (Student's $t$ test, $P>0.05$ )

n.t. $=$ not tested.

Table 3. Severity of foliage damage by Japanese beetles on primocane blackberry cultivars in 2017 and 2018 in Mountain Grove, MO. Average damage \pm SE. Measure was estimated by rating on a scale from 1 (the least damage) to 5 (the most severe damage) $(\mathrm{N}=66-130)$.

\begin{tabular}{lccc}
\hline & \multicolumn{2}{c}{ Avg damage \pm SE (points) } & Damage increase ratio \\
\cline { 2 - 3 } Cultivar & 2017 & 2018 & NS \\
\hline APF-40 & $1.81 \pm 0.08$ a A & $1.68 \pm 0.07$ a A & \\
Prime-Ark 45 & $1.82 \pm 0.06$ a & n.t. & NS \\
Prime-Jim & $1.83 \pm 0.09$ a & n.t. & P \\
Prime-Jan & $2.24 \pm 0.10 \mathrm{~b} \mathrm{~A}$ & $2.35 \pm 0.12 \mathrm{~b} \mathrm{~A}$ & \\
\hline
\end{tabular}

Statistical significance of damage among the cultivars in a given year is indicated by lowercase letters. Values in columns followed by the same lowercase letters are not statistically significant (analysis of variance followed by Tukey comparison of means, $P>0.05)$. Statistical significance of damage in the same cultivars between 2017 and 2018 is indicated by uppercase letters. Values in rows followed by the same uppercase letters are not statistically significant (Student's $t$ test, $P>0.05$ ).

n.t. $=$ not tested; NS $=$ not significant
'Apache' (Table 4; Tukey, $\mathrm{F}=50.7, \mathrm{df}=$ 452, $P<0.05)$.

The trap catches of Japanese beetles in 2018 were nearly 2-fold greater than in 2017 (Fig. 2), but the severity of foliage damage increased only in 'Ouachita' - by a factor of 1.43 (Table 4; Student's $t$ test, $\mathrm{t}=3.48, \mathrm{df}=$ 192, $P<0.05)$. There were only slight, insignificant differences in damage severity rating in 'Osage' and 'Apache' (Table 4; Student's $t$ test, $\mathrm{t}=1.84, \mathrm{df}=243, P>0.05$; and $\mathrm{t}=1.26$, df $=282, P>0.05$, respectively).

Cultivar preference. Out of two primocane cultivars we studied, significantly more Japanese beetles preferred 'Prime-Jan' than 'APF-40' during the period corresponding to a CDD range of 998 to 1142 (Fig. 3; Student's $t$ test, $\mathrm{t}=2.33$, df $=18, P<0.05$; and $\mathrm{t}=3.41$, $\mathrm{df}=18, P<0.01$, respectively). In floricane cultivars, there were significantly more Japanese beetles feeding on 'Apache' than 'Ouachita' for almost the entire duration of the experiment (Fig. 3; Student's $t$ test, $\mathrm{t}=1.8$, $\mathrm{df}=18, P<0.001 ; \mathrm{t}=3.7, \mathrm{df}=18, P<0.01$; $\mathrm{t}=2.4, \mathrm{df}=18, P<0.01 ; \mathrm{t}=2.4, \mathrm{df}=18, P<$ $0.05 ; \mathrm{t}=3.1, \mathrm{df}=18, P<0.01 ; \mathrm{t}=3.2, \mathrm{df}=$ $18, P<0.01$, and $\mathrm{t}=2.5, \mathrm{df}=18, P<0.05$, respectively).

In addition, there were significantly more Japanese beetles feeding on 'Apache' blackberries than on 'Prime-Jan' at the beginning (CDD, 814) (Fig. 3; Student's $t$ test, $\mathrm{t}=3.7$, df $=18, P<0.01)$ and the end (CDD, 1251) (Fig. 3; Student's $t$ test, $\mathrm{t}=3.7, \mathrm{df}=18$, $P<0.05)$ of the experiment.

\section{Discussion}

Exposure of the blackberries to the Japanese beetle. Our findings indicate that the blackberry planting in the Mountain Grove research campus farm faced severe pressure from Japanese beetles. The numbers of Japanese beetles caught within a 24-h period increased from six to more than 20,000 in 2017 and from eight to more than 45,000 in 2018 . These were much greater trap catches than those reported by Johnson et al. (2010) for several locations in northwestern Arkansas monitored for the Japanese beetle in 2005. They reported that 2005 peak counts varied from 20,000 to 40,000 beetles/trap/week, which translates to 2857 to 5714 beetles/trap/day on average). It is difficult to compare their data with ours, because the trap design and lure used by Johnson et al. (2010) differed from our trapping system. However, it seems likely that the Japanese beetle pressure in the Mountain Grove blackberry planting was much greater than that in the Arkansas study (Johnson et al., 2010).

Blackberry foliage damage. There were authors are unaware of any reports of blackberry feeding incidence by Japanese beetles. However, reports from other authors indicate that the Japanese beetle can exhibit different feeding incidence on different plant cultivars. For instance, $\mathrm{Gu}$ and Pomper (2008) found that feeding incidence by the Japanese beetle on 33 cultivars of grapes varied from $42 \%$ to 
Table 4. Severity of foliage damage by Japanese beetles on floricane blackberry cultivars in 2017 and 2018 in Mountain Grove, MO. Average damage \pm SE. Measurement was estimated by rating on a scale from 1 (the least damage) to 5 (the most severe damage) $(\mathrm{N}=73-166)$.

\begin{tabular}{|c|c|c|c|}
\hline \multirow[b]{2}{*}{ Cultivar } & \multicolumn{2}{|c|}{ Avg damage \pm SE (points) } & \multirow[b]{2}{*}{ Damage increase ratio } \\
\hline & 2017 & 2018 & \\
\hline Ouachita & $1.25 \pm 0.14$ a A & $1.79 \pm 0.09$ a B & 1.43 \\
\hline Natchez & $2.12 \pm 0.09 \mathrm{~b}$ & n.t. & \\
\hline Kiowa & $2.12 \pm 0.92 b$ & n.t. & \\
\hline Chickasaw & $2.28 \pm 0.11 \mathrm{~b}$ & n.t. & \\
\hline Osage & $2.36 \pm 0.13 \mathrm{~b} \mathrm{~A}$ & $2.08 \pm 0.09 \mathrm{a} \mathrm{A}$ & Ns \\
\hline Triple Crown & $2.40 \pm 0.13 \mathrm{~b}$ & n.t. & \\
\hline Arapaho & $2.44 \pm 0.10 b$ & n.t. & \\
\hline Chester & $2.50 \pm 0.08 \mathrm{~b}$ & n.t. & \\
\hline Apache & $3.23 \pm 0.13 \mathrm{c} \mathrm{A}$ & $3.03 \pm 0.10 \mathrm{~b} \mathrm{~A}$ & Ns \\
\hline
\end{tabular}

Statistical significance of damage among the cultivars in a given year is indicated by lowercase letters. Values in columns followed by the same lowercase letters are not statistically significant (analysis of variance followed by Tukey comparison of means, $P>0.05$ ). Statistical significance of damage in the same cultivars between 2017 and 2018 is indicated by uppercase letters. Values in rows followed by the same uppercase letters are not statistically significant (Student's $t$ test, $P>0.05$ ). n.t. $=$ not tested.

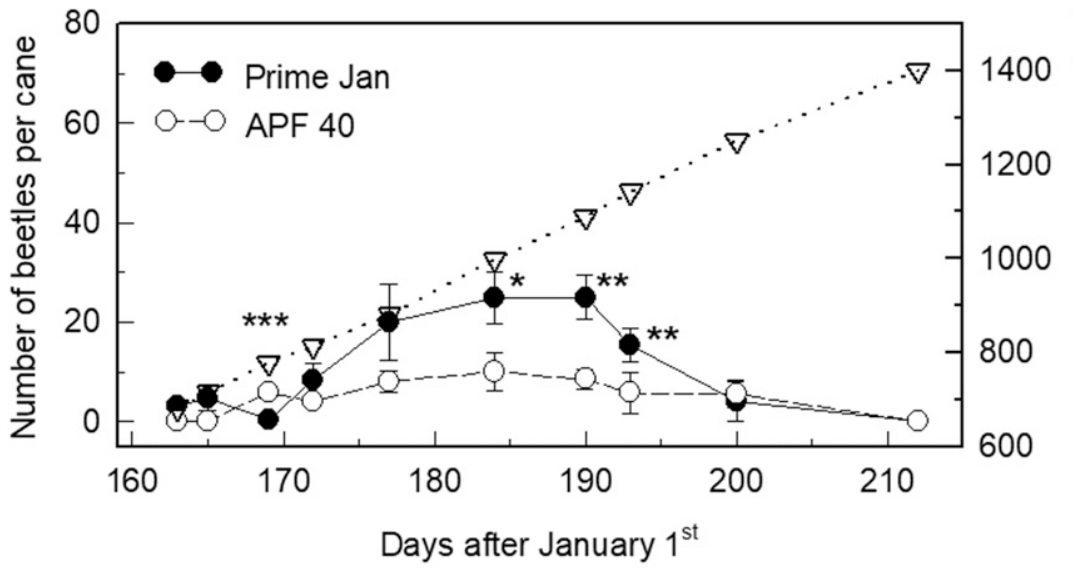

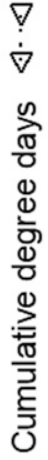

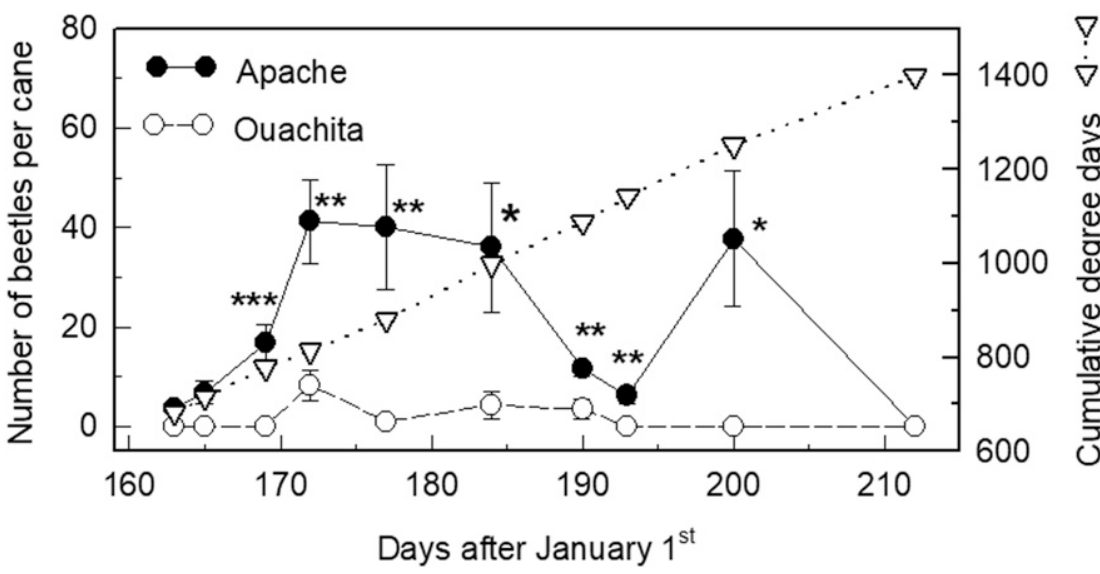

Fig. 3. Cultivar preference noted as average numbers of Japanese beetles \pm SE on the blackberry plantation in Mountain Grove, MO, in 2018 among two primocanes (upper panel) and two floricanes (lower panel) each vs. cumulative degree-days since 1 Jan. (triangles) (Student's $t$ test, ${ }^{*} P<0.05,{ }^{* *} P<0.01$, $* * * P<0.001 ; \mathrm{N}=10$ ).

$94 \%$, depending on the cultivar. Moreover, there was a positive correlation between percentage of damaged leaves and the severity rating of leaf damage. In the field, the cultivars with a low feeding incidence attracted about five times fewer Japanese beetles than those with a high feeding incidence. The results of $\mathrm{Gu}$ and Pomper (2008) suggest that percentage of damaged leaves reflected the attractiveness of a given grape cultivar, and that if the beetles were attracted to a particular cultivar, they fed on it, and they did not explore more feeding opportunities. In our study, feeding incidence was similar in all the blackberry cultivars investigated, in both 2017 and 2018, suggesting that all the cultivars attracted Japanese beetles with the same moderate efficacy (Tables 1 and 2). However, incidence of damage was significantly greater in 2018 than in 2017, indicating that pressure from the Japanese beetle on the blackberries correlated with the greater trap beetle counts in 2018 .

Johnson et al. (2010) studied the percentage of blackberry canopy damaged by Japanese beetles feeding on blackberries. Direct comparison of the results between their work and ours is difficult, because Johnson et al. (2010) rated the damage of the entire canopy visually, not that of particular leaves. However, some similarities between their results and our data are evident. For instance, in both studies, 'Apache' showed the greatest susceptibility to Japanese beetles, whereas 'Ouachita' was the most resistant of the floricanes. In both studies, 'Chickasaw' and 'Arapaho' showed similar resistance to Japanese beetles, which was greater than that exhibited by 'Apache', but significantly lower than that of 'Ouachita'. Our results for primocanes differ from those presented by Johnson et al. (2010). In their study, 'Prime-Jim' was more susceptible than 'Prime-Jan', whereas our study indicates the exact opposite.

Interestingly, despite greater pressure from Japanese beetles in 2018, severity of foliage damage increased only in 'Ouachita' (Table 4). This finding suggests that the blackberry cultivars we tested succumb to the Japanese beetle only to a certain degree, and that after reaching a certain degree of damage, the plants may start producing some antifeedants, preventing further damage (Purrington, 2003). That turning point might have not been reached in 'Ouachita'; therefore, in 2018, the damage severity was greater than that in 2017.

Blackberry cultivar preference. The results of the experiment with cultivar preference correspond well with the results for incidence and severity of foliage damage. With regard to Prime-Jan, a cultivar more sensitive to Japanese beetles, there were significantly more beetles than 'APF-40', which suffered less damage both in 2017 and in 2018. Similarly, with regard to the more-sensitive 'Apache', there were more beetles than on the less-sensitive 'Ouachita'.

Closing remarks. One additional aspect of this study is notable. In both 2017 and 2018, all blackberry cultivars exhibited similar feeding incidence, but different feeding severity. This finding suggests that the Japanese beetle does not differentiate among blackberry cultivars from a distance, but does upon contact with the foliage of a given plant. Consequently, we cannot exclude the possibility that the relative resistance of 'APF-40' and 'Ouachita' to Japanese beetles is the result of some intrinsic chemical or physical characteristics of the foliage. At this stage of our research, we think the characteristics that cause relative resistance to Japanese beetles are secondary metabolites, or perhaps the texture or nutritional value of the foliage. Pettis et al. (2004) reported that the Japanese beetle does not discriminate among cultivars of myrtle, despite significant differences in concentrations of nutrients and microelements in the foliage of the cultivars they studied. In our minds, plant secondary metabolites are the 
most likely candidates for factors influencing blackberry cultivar preference and damage by Japanese beetles. This issue is a subject for further experimentation. Currently, we believe that additional blackberry cultivars should be evaluated to identify those resistant to the Japanese beetle.

\section{Literature Cited}

Clark, J.R. and C.E. Finn. 2011. Blackberry breeding and genetics. Fruit, Veg. Cereal Sci. Biotech. 5:27-43.

Fleming, W.E. 1972. Biology of the Japanese beetle. USDA Tech. Bul. no. 1449. U.S. Govt. Printing Office, Washington, D.C.
Fleming, W.E. 1976. Integrating control of the Japanese beetle: A historical review. USDA Tech. Bul. no. 1445. U.S. Govt. Printing Office, Washington, D.C.

$\mathrm{Gu}$, S. and K.W. Pomper. 2008. Grape cultivar feeding preference of adult Japanese beetles. HortScience 43:196-199.

Johnson, D.T., C.R. Rom, J. Mcafee, J. Mckern, E.T. Stafne, and J.R. Clark. 2010. Differences in defoliation of fruit genotypes by adult Japanese beetle feeding. J. Amer. Pomol. Soc. 64:184-198.

Ludwig, D. 1928. The effects of temperature on the development of an insect (Popillia japonica Newman). Physiol. Zool. 1:358-389.

Pettis, G.V., D.W. Boyd, Jr., S.K. Braman, and C. Pounders. 2004. Potential resistance of crape myrtle cultivars to flea beetle (Coleoptera: Chrysomelidae) and Japanese beetle (Coleoptera: Scarabaeidae) damage. J. Econ. Entomol. 97:981-992.

Potter, D.A. and D.W. Held. 2002. Biology and management of the Japanese beetle. Annu. Rev. Entomol. 47:175-205.

Purrington, C.B. 2003. Antifeedant substances in plants, p. 1140-1145. In: B. Thomas (ed.). Encyclopedia of applied plant sciences. Academic Press, Cambridge, MA.

Strik, B.C., J.R. Clark, C.E. Finn, and M.P Bañados. 2007. Worldwide blackberry production. HortTechnology 17:205-213.

Tashiro, H. 1987. Turfgrass insects of the United States and Canada. Cornell University Press, New York, NY. 